\section{Patient adherence in the treatment of depression}

\author{
S. PAMPALLONA, P. BOLLINI, G. TIBALDI, B. KUPELNICK and C. MUNIZZA
}

Background Non-adherence with antidepressant treatment is very common. Increasing adherence to pharmacological treatment may affect response rate.

\begin{abstract}
Aims To review and summarise quantitative evidence on factors associated with adherence and of adherence-enhancing interventions.

Method A systematic review of computerised databases was carried out to identify quantitative studies of adherence in depression. Papers retained addressed unipolar depression and considered adherence as the primary end-point.
\end{abstract}

Results Of studies published between 1973 and 1999, 32 met the review criteria: epidemiological descriptive studies $(n=14)$ : non-random comparisons of control and intervention groups $(n=3)$; randomised interventions ( $n=14)$; and meta-analysis $(n=1)$. Patient education and medication clinics were the interventions most commonly tested, combined with a variety of other interventions.

\section{Conclusions The studies did not give consistent indications of which interventions may be effective. Carefully designed clinical trials are needed to clarify the effect of single and combined interventions.}

\footnotetext{
Declaration of interest The study was partially supported by Centro Studi e Ricerche in Psichiatria, Turin; Istituto Superiore di Sanità, Rome; and Ravizza Pharmaceuticals, Milan.
}

Adherence may be defined as the extent to which a person's behaviour conforms to medical or health advice (Bruer, 1982). Four meta-analyses (Anderson \& Tomenson, 1995; Montgomery \& Kasper, 1995; Steffens et al, 1997; Anderson, 1998) have demonstrated that for tricyclic antidepressants (TCAs) and selective serotonin reuptake inhibitors (SSRIs), drop-out rates are in the range of $21-33 \%$, irrespective of the drug class. A subsequent meta-analysis showed that $20 \%$ of patients did not improve and $30 \%$ dropped out of treatment for a variety of reasons (Bollini et al, 1999). The drop-out rate is contributed to by factors such as illness and patients' characteristics, side-effects, time taken to improve or the patient-doctor relationship (Demyttenaere, 1997). The magnitude and complexity of the problem prompted this review of the available literature. The aim was to collect and synthesise quantitative information concerning factors associated with and interventions affecting adherence to antidepressants.

\section{METHOD}

\section{Identification of relevant publications}

In order to obtain the most exhaustive yield of papers addressing adherence in the treatment of depression, we first explored general textbooks on depression and on treatment adherence. Subsequently, multiple systematic searches of Medline, Current Contents, PsychInfo, and the Cochrane Collaborative Register of Trials were performed, restricted to the period from January 1990 to December 1999. The searches included the following medical subject headings: patient compliance, depressive disorders, psychotherapy, mental health services, randomised clinical trials, prospective studies, research designs and meta-analysis. About 5000 publications were identified. In addition, a systematic scrutiny of all the references of all the papers retrieved provided additional relevant studies. A total of 381 articles were judged potentially eligible for this review and read independently by two of us. The criteria to retain a publication were: that it addressed unipolar depression (either as the exclusive diagnostic category or as a substantial part of the diagnoses) and considered adherence rate (as opposed to response rate) as a primary end-point. The selected studies were classified into five mutually exclusive categories, according to the structure and informative content of each paper:

(a) descriptive epidemiological study, addressing factors associated with adherence;

(b) non-randomised intervention;

(c) randomised intervention (both (b) and (c) aimed at testing the effectiveness of interventions to improve adherence);

(d) meta-analysis;

(e) qualitative articles, such as editorials or review papers.

This report focuses on publications in categories (a)-(d).

\section{Data extraction and synthesis}

For all types of study we developed an ad boc data extraction form. The main information extracted concerned the setting of the study, a clinical and demographic description of the patient sample, the length of the observation, response rate, adherence rate and the factors associated with adherence (for descriptive epidemiological studies only). As concerns adherence data, each study applied its own definition and rates were extracted as reported in the original publications. The measures of adherence were grouped into five categories:

(a) appointments kept (whether patients respected a pre-set schedule of visits);

(b) pills taken (any measure of adherence based on direct count of pills actually taken);

(c) plasma levels (any parameter measuring concentration of drug in blood);

(d) protocol deviation (termination of treatment before planned treatment period);

(e) composite index (ad hoc composite scales comprising any measure of intake of drug and other indicators such as patient satisfaction, reasons for stopping treatment, knowledge about drugs, satisfaction with treatment, etc.). 
The methodological strength of the papers was evaluated on the basis of whether the sample size computations were reported. This aspect is of relevance since the smaller the expected difference in adherence rate among subgroups (for descriptive epidemiological studies) or between treatment arms (for non-randomised and randomised intervention studies) the larger the sample size should be for there to be a reasonable chance of detecting it. For randomised intervention studies we also considered whether a description of the randomisation procedure was reported.

For non-randomised and randomised studies we grouped the interventions into seven categories: (a) psychological treatment; (b) patient education; (c) education of the patient's family; (d) training of physicians; (e) training of nurses; (f) changes in patient management (e.g. case management, change in the frequency of follow-up, etc.); and (g) medication clinics (scheduled meetings with the patient to adjust medication and control side-effects). Given the multi-modality of the interventions, we adopted the following approach to assess the relative effect on adherence of their components. First, all pairwise comparisons for every trial were constructed. Two-arm trials therefore contributed one pairwise comparison each: trials that compared three arms (say arms A, B and C) contributed three pairwise comparisons (namely A $v$. B, A $v$. C and B $v$. C). Similarly, the single trial with four arms contributed six pairwise comparisons. Subsequently, we defined as offset of a pairwise comparison the component of the intervention common to both arms being compared. For instance, a trial where drug treatment plus education of patients was compared with drug treatment alone was classified as having drug treatment as an offset. We defined as contrast the actual interventions being compared ignoring the common offset. For the same example, the contrast would be patient education $v$. no intervention.

Data were extracted and reviewed by two of us (S.P. \& P.B.), and disagreements resolved with discussion. An ad hoc database was created for the data extracted, linked to a commercial database containing all the relevant references. Given the nature of the material found, no formal metaanalytical approach was justified, and no specific statistical analysis tools have been used.

\section{RESULTS}

\section{Characteristics of the studies}

All the sources considered provided a total of 32 eligible studies published between 1973 and 1999. Epidemiological descriptive studies accounted for 14 of the reviewed studies; three studies were nonrandomised comparisons and randomised interventions accounted for 14 studies. Only one meta-analysis was retained. Almost half of the studies were conducted in the USA, and 10 in the UK. Three other studies were conducted in Canada, and three in Europe. About two-thirds of the descriptive and randomised studies, respectively, were published in the 1990s.

The studies reviewed were conducted in a variety of settings, with the majority taking place in out-patient psychiatric services $(n=12)$ and psychiatric hospitals $(n=8)$, and the remainder in primary care settings. The diagnostic categories employed in the studies are reviewed in Table 1 . The category 'mixed diagnoses with depression' includes studies that considered other diagnoses besides depression (schizophrenia, bipolar disorders, etc.). With regard to measures of adherence, a majority of studies employed direct measures of drug intake, that is, the number of pills taken. Epidemiological studies employed quite often the number of appointments kept. Finally, only four studies used composite measures of drug intake and other indices.

The duration of observation varied considerably, from 2 to 104 weeks. Overall, patients were observed for more than 24 weeks in eight studies out of 31 (the meta-analysis is excluded). The median duration of observation was 12 weeks.

\section{Methodological strength of descriptive epidemiological studies, non-randomised and randomised intervention studies}

Epidemiological studies considered a total of 10119 patients, with sample sizes varying from 27 to 4052 subjects. Non-randomised studies totalled 190 subjects, with a range of 23 to 100 patients. Evidence from randomised studies - the best source of information - was based on only 2145 patients and sample size varied from 14 to 649 , a median of 120 patients. Sample size computations were performed and adequately reported in only two

Table I Diagnostic category and adherence measure by study design (excluding the single meta-analysis)

\begin{tabular}{|c|c|c|}
\hline Design & Diagnosis/measure of adherence & Studies $(n)$ \\
\hline \multirow[t]{4}{*}{ Descriptive study } & Major depression & 2 \\
\hline & Minor and major depression & 3 \\
\hline & Mixed diagnoses with depression & 5 \\
\hline & Unspecified depressive disorder & 4 \\
\hline \multirow[t]{2}{*}{ Non-randomised intervention } & Mixed diagnoses with depression & 2 \\
\hline & Unspecified depressive disorder & 1 \\
\hline \multirow[t]{4}{*}{ Randomised intervention } & Major depression & 3 \\
\hline & Minor and major depression & 2 \\
\hline & Mixed diagnoses with depression & 3 \\
\hline & Unspecified depressive disorder & 6 \\
\hline Total & & 31 \\
\hline \multirow[t]{4}{*}{ Descriptive study } & Appointments kept & 5 \\
\hline & Pills taken & 6 \\
\hline & Plasma levels & 2 \\
\hline & Composite index(es) & I \\
\hline \multirow[t]{2}{*}{ Non-randomised intervention } & Appointments kept & 1 \\
\hline & Pills taken & 2 \\
\hline \multirow[t]{5}{*}{ Randomised intervention } & Appointments kept & 1 \\
\hline & Pills taken & 8 \\
\hline & Plasma levels & I \\
\hline & Protocol deviation & 1 \\
\hline & Composite index(es) & 3 \\
\hline Total & & 31 \\
\hline
\end{tabular}


Table 2 Factors associated with adherence in 14 descriptive epidemiological studies

\begin{tabular}{|c|c|c|c|}
\hline \multirow[t]{2}{*}{ Study } & \multirow[t]{2}{*}{ Factors associated with better adherence } & \multicolumn{2}{|c|}{ Adherence Sample } \\
\hline & & (\%) & size \\
\hline Voris et al, 1983 & Not studied & 35 & 100 \\
\hline Johnson, I98I & Not studied & 68 & 112 \\
\hline Craig et al, 1974 & Not studied & 42 & 238 \\
\hline Engstrom, |99| & Not studied & 74 & 27 \\
\hline Hall et al, 1990 & Not studied & 97 & 29 \\
\hline Melfi et al, 1998 & Lack of relapse & 30 & 4052 \\
\hline Maddox et al, 1994 & Lack of severe side-effects & 52 & 46 \\
\hline Croghan et al, 1997 & Use of fluoxetine rather than other antidepressant drugs & 44 & 1242 \\
\hline Last et al, 1985 & High education, high IQ, good social adjustment & 66 & 125 \\
\hline Robinson et al, 1995 & No side-effects, previous use of antidepressants & 51 & 164 \\
\hline Tedlow et al, 1996 & Lower rates of narcissistic-histrionic personality disorders & 87 & 210 \\
\hline Blouin et al, 1985 & $\begin{array}{l}\text { Female gender, referral to a private psychiatrist, current } \\
\text { psychiatric treatment }\end{array}$ & 59 & 468 \\
\hline Simon et al, 1993 & $\begin{array}{l}\text { Prescription by a psychiatrist, prescription of imipramine, } \\
\text { nortriptyline, fluoxetine }\end{array}$ & 41 & 2432 \\
\hline Matas et al, 1992 & $\begin{array}{l}\text { Married status, non-emergency referral, diagnosis other } \\
\text { than personality disorder and substance abuse }\end{array}$ & 82 & 874 \\
\hline
\end{tabular}

Table 3 Three contrasts and corresponding offsets in three non-randomised clinical trials

\begin{tabular}{|c|c|c|c|}
\hline Contrast & Offset & Comparisons (n) & $\%$ adherence \\
\hline Education of patient $v$. no intervention & Drug treatment & I & 82 v. 68 \\
\hline Psychological treatment v. no intervention & Drug treatment & 1 & 73 v. 8 \\
\hline $\begin{array}{l}\text { Psychological treatment plus education of } \\
\text { patient } v \text {. no intervention }\end{array}$ & Drug treatment & $\mathbf{I}$ & 66 v. 9 \\
\hline
\end{tabular}

randomised studies, while none of the other papers, whether a descriptive epidemiological or non-randomised intervention study, mentioned the expected effect on adherence of the factors or of the interventions respectively. Only three of the randomised studies described explicitly the procedure for randomisation.

\section{Descriptive epidemiological studies}

The main results of the 14 descriptive studies reviewed are reported in Table 2 . The table suggests a very wide range of adherence rates (from 30 to $97 \%$, median $63 \%$ ). Factors positively and significantly associated with increased adherence were reported in nine studies; no systematic pattern was disclosed from the study of the factors identified. The relationship between adherence and response was reported in only one study. with the same offset. It was therefore not possible to combine homogeneous data across studies.

The six comparisons for which data were available comparing patient education with no intervention (with drug treatment only as the common offset) could, in theory, contribute to a pooled estimate of the effect of patient education. However, they showed such different adherence rates in the 'no intervention' group, that we felt any formal meta-analytical effort would not be meaningful.

As a final remark, it should be noted that in Tables 3 and 4 those arms without or with fewer interventions (irrespective of the offset) almost invariably showed lower adherence rates.

\section{Meta-analyses}

We identified only one relevant metaanalysis (Roter et al, 1998), reporting results of 135 studies published between 1977 and 1994 on different medical conditions and on a variety of treatment regimens. Thirteen studies on mental health were part of the meta-analysis, including two randomised trials in depression, which have been already reviewed above as part of the randomised interventions.

\section{DISCUSSION}

\section{Interpretation of the results}

This review had three main findings. First, it confirmed that adherence is a major problem in the treatment of depression. Although drugs are commonly considered a critical tool in the treatment of depression, evidence from descriptive epidemiological studies confirmed that about one in three patients could not complete treatment. Second, in spite of its magnitude and of its worrisome implications in terms of morbidity and disability, adherence has rarely been the object of specific research, especially when compared with the vast amount of studies on the effectiveness of antidepressant drugs. Third, the few quantitative studies on adherence (non-randomised and randomised interventions) do not provide either reliable or consistent indications as to the efficacy of specific interventions or combinations thereof. They do, however, consistently point in the direction that adherence can indeed be increased through interventions supporting the prescription of antidepressants. 
Table 4 Twenty-five comparisons and corresponding offsets in 14 randomised clinical trials

\begin{tabular}{|c|c|c|c|}
\hline Contrast & Offset & Comparisons (n) & $\%$ adherence \\
\hline \multirow[t]{4}{*}{ Drug treatment $v$. drug treatment ${ }^{1}$} & Education of patient & 3 & 29 v. 44 \\
\hline & & & 42 v. 44 \\
\hline & & & 42 v. 29 \\
\hline & No intervention & $\mathbf{I}$ & 55 v. 83 \\
\hline \multirow[t]{2}{*}{ Education of patient $v$. education of patient ${ }^{2}$} & Drug treatment & 2 & 65 v. 65 \\
\hline & & & 32 v. 34 \\
\hline Education of patient $v$. medication clinic & Drug treatment plus training of nurses & I & 42 v. 65 \\
\hline \multirow[t]{8}{*}{ Education of patient $v$. no intervention } & Drug treatment & $7^{3}$ & 65 v. 48 \\
\hline & & & 65 v. 48 \\
\hline & & & 32 v. 32 \\
\hline & & & 34 v. 32 \\
\hline & & & 88 v. 80 \\
\hline & & & 61 v. 28 \\
\hline & Drug treatment plus training of nurses plus & $\mathrm{I}$ & 60 v. 65 \\
\hline & medication clinic & & \\
\hline Education of patient $v$. psychological treatment & Drug treatment & $\mathrm{I}$ & 37 v. 22 \\
\hline $\begin{array}{l}\text { Education of patient plus education of family plus patient } \\
\text { management plus psychological treatment } v \text {. no intervention }\end{array}$ & Drug treatment & I & 37 v. 22 \\
\hline $\begin{array}{l}\text { Education of patient plus management changes plus medication } \\
\text { clinic } v \text {. no intervention }\end{array}$ & Drug treatment & I & 69 v. 44 \\
\hline Education of patient plus medication clinic $v$. no intervention & Drug treatment plus training of physicians & 1 & 76 v. 50 \\
\hline Medication clinic v. no intervention & $\begin{array}{l}\text { Drug treatment plus training of nurses plus education } \\
\text { of patient }\end{array}$ & 1 & 60 v. 41 \\
\hline $\begin{array}{l}\text { Psychological treatment plus education of patient plus education } \\
\text { of family plus medication clinic } v \text {. no intervention }\end{array}$ & Drug treatment plus training of physicians & 1 & 70 v. 46 \\
\hline Training of nurses plus education of patient $v$. no intervention & Drug treatment & I & 42 v. 36 \\
\hline $\begin{array}{l}\text { Training of nurses plus education of patient plus medication clinic } \\
\text { v. no intervention }\end{array}$ & Drug treatment & I & 60 v. 36 \\
\hline \multirow[t]{2}{*}{ Training of nurses plus medication clinic $v$. no intervention } & Drug treatment & 2 & 50 v. 55 \\
\hline & & & 65 v. 36 \\
\hline
\end{tabular}

I. This was a three-arm study, where patients were randomised to amitriptyline (or mianserin, if at risk of overdose) once-a-day drug treatment, three-times-a-day drug treatment, or whatever schedule they chose.

2. In one study patients were randomised to two different educational messages: information on either drug side-effects or beneficial drug effects. In the second study patients were randomised to two different ways of providing information: either an information sheet describing the class of medication patients were discharged on, or the same plus a review of the written information provided by a nurse or a psychologist.

3. One study did not report adherence results.

\section{Quality of the evidence}

It was not possible to extract meaningful indications on factors associated with nonadherence from epidemiological studies because each study considered its own set of potential predictors. Additionally, the important relationship between adherence and outcome of treatment has been evaluated only in one study. The methodological quality of the literature on medication adherence can be evaluated by means of a recently published scoring system (Nichol et al, 1999). This score has not been applied here because its items are oriented to the evaluation of pharmacological treatments through physical and laboratory measurements. The majority of the comparative studies that we considered presents interventions other than pharmacological, and would thus score very low. We therefore assessed the methodological strength of the papers considering sample size computation and randomisation procedure - the results pointed to the poor methodological strength of the available contributions.

\section{Complexity of study design}

Intervention studies, and in particular randomised clinical trials, investigated a variety of interventions to improve adherence. The exception was one study where the intervention to increase adherence involved the administration of amitriptyline $v$. fluoxetine. Many studies, by implementing several interventions at the same time, could not provide evidence on the separate effects of each of the components. This leaves unaddressed the questions on which is the effect of each component and whether all of them are needed in combination, a common problem in the adherence literature (Haynes et al, 1996). Even looking at contrasts, as we have done, does not help to disentangle the effect of each component. The concept of contrasts allows the identification of the 'unconfounded' components of each trial (Haynes et al, 1996), that is, of the difference in terms of 
interventions between two arms of a trial. However, the offset may act on adherence in both arms of the trial being compared and perhaps synergistically so with the unconfounded component. The role of the offset can, therefore, hardly be allowed for. To complicate matters, the same contrast may also be paired with different offsets across studies: depending on the offset, the magnitude of the effect attributable to a given contrast may therefore vary from study to study. Finally, the studies addressed both minor and major depression as well as mixed diagnoses, making it difficult to assess whether specific interventions were more appropriate for specific diagnostic groups. Tables 3 and 4 none the less contain a consistent trend: the arm with more interventions generally showed a higher adherence rate. This suggests that improvements in adherence rates can indeed be achieved through the kinds of intervention considered in the literature.

\section{Recommendations}

Much is still to be done in the field of treatment adherence in depressive disorders. Successive classes of antidepressant have only marginally increased the proportion of patients actually benefiting from pharmacological treatment (Greenberg \& Fisher, 1997). It is unrealistic to hope that a new drug may by itself reduce substantially the big proportion of patients who do not adhere to treatment. Carefully designed clinical trials are therefore needed to clarify the effect of single and combined interventions on adherence, as well as to further investigate the factors affecting adherence. Such studies and the proposed interventions should be feasible in busy clinical practices where the majority of patients are seen (Kendrick, 2000) and where adherence problems may be even more acute than in the setting of the common therapeutic clinical trials. Increasing the number of patients who are put in a position to better adhere to the prescribed treatment could in turn increase the response rate to antidepressant drugs (Haynes et al, 1996).

\section{APPENDIX - STUDIES REVIEWED}

\section{Meta-analysis}

Roter, D. L., Hall, J. A., Merisca, R., et al (1998)

Effectiveness of interventions to improve patient compliance. Medical Care, 36, II38-1161.

\section{CLINICAL IMPLICATIONS}

A large variety and combinations of interventions have been proposed by the investigations considered in this review.

- No clear indication has emerged concerning which specific interventions or combinations thereof contribute to improve adherence, though evidence suggests that it can be improved.

- Further research should address both the causes of non-adherence to antidepressant drugs and the interventions affecting it.

\section{LIMITATIONS}

- The studies considered applied different measures of adherence including: bedside pill counts or blood drug levels, behavioural indicators, psychological symptoms, subjective evaluations or adherence to a pre-defined schedule of appointments.

- The possible relationship between the non-adherence rate and drug regimen (dose, duration, side-effects, etc.) could not be addressed given the design of the investigations considered in this review.

- This review does not provide evidence on whether an increase in adherence corresponds to an increase in response rate.

S. PAMPALLONA, ScD, P. BOLLINI, DrPH, forMed Statistics for Medicine, Evolène, Switzerland; G. TIBALDI, MD, B. KUPELNICK, BA, C. MUNIZZA, MD, Centro Studi e Ricerche in Psichiatria, Turin, Italy

Correspondence: Dr Carmine Munizza, Centro Studi e Ricerche in Psichiatria, Piazza del Donatore di Sangue 3, 10154 Torino, Italy

(First received I5 November 2000, final revision 19 March 200I, accepted 6 April 200I)

\section{Descriptive studies}

Blouin, A., Perez, E. \& Minoletti, A. (1985)

Compliance to referrals from the psychiatric emergency room. Canadian Journal of Psychiatry, 30, 103-106.

\section{Craig, T. G., Huffine, C. L. \& Brooks, M. (1974)}

Completion of referral to psychiatric services by inner

city residents. Archives of General Psychiatry, 31, 353-357.

Croghan, T. W., Lair, T. J., Engelhart, L., et al (1997)

Effect of antidepressant therapy on health care utilization and costs in primary care. Psychiatric Services, 48, 1420-1426.

Engstrom, F. W. (1991) Clinical correlates of antidepressant compliance. In Patient Compliance in Medical Practice and Clinical Trials (eds J. A. Cramer \& B. Spilker), pp. 187-194. New York: Raven Press.

Hall, D., Wiles, D. H. \& McCreadie, R. G. (1990) Compliance with antidepressant medication (letter) British Journal of Psychiatry, 157, 453-454.

Johnson, D. A. W. (198I) Depression: treatment compliance in general practice. Acta Psychiatrica Scandinavica, 290 (suppl. 63), 447-453.

Last, C. G., Thase, M. E., Hersen, M., et al (1985) Patterns of attrition for psychosocial and pharmacologic treatments of depression. Journal of Clinical Psychiatry, 46, 36I-366.
Maddox, J. C., Levi, M. \& Thompson, C. (1994) The compliance with antidepressants in general practice. Journal of Psychopharmacology, 8, 48-53.

Matas, M., Staley, D. \& Griffin, W. (1992) A profile of the noncompliant patient: a thirty-month review of outpatient psychiatry referrals. General Hospital Psychiatry, 14, 124-130.

Melfi, C. A., Chawla, A. J. Croghan, T.W., et al (1998) The effects of adherence to antidepressant treatment guidelines on relapse and recurrence of depression. Archives of General Psychiatry, 55, II28-1/32.

Robinson, P., Bush, T., Von Korff, M., et al (1995) Primary care physician use of cognitive behavioral techniques with depressed patients. Journal of Family Practice, 40, 352-357.

Simon, G. E., Von Korff, M., Wagner, E. H., et al (1993) Patterns of antidepressant use in community practice. General Hospital Psychiatry, 15, 399-408.

Tedlow, J. R., Fava, M., Uebelacker, L. A., et al (1996) Are study dropouts different from completers? Biological Psychiatry, 40, 668-670.

Voris, J. C., Morin, C. \& Kiel, J. S. (1983) Monitoring outpatients' plasma antidepressant-drug concentrations as a measure of compliance. American Journal of Hospital Pharmacy, 40, I19-120. 


\section{Non-randomised interventions}

Daley, D. C., Salloum, I. M., Zuckoff, A., et al (1998)

Increasing treatment adherence among outpatients with depression and cocaine dependence: results of a pilot study. American Journal of Psychiatry, 155, 1611-1613.

Myers, E. D. \& Calvert, E. J. (1976) The effect of forewarning on the occurrence of side-effects and discontinuance of medication in patients on dothiepin. International Journal of Medical Research, 4, 237-240.

Seltzer, A., Roncari, I. \& Garfinkel, P. (1980) Effect of patient education on medication compliance. Canadian Journal of Psychiatry, 25, 638-645.

\section{Randomised interventions}

Altamura, A. C. \& Mauri, M. (1985) Plasma concentrations, information and therapy adherence during long-term treatment with antidepressants. British Journal of Clinical Pharmacology, 20, 714-716.

Demyttenaere, K., Van Ganse, E., Gregoire, J., et a (1998) Compliance in depressed patients treated with fluoxetine or amitriptyline. International Clinical Psychopharmacology, 13, II-17.

Katon, W., Von Korff, M., Lin, E., et al (1995) Collaborative management to achieve treatment guidelines. Impact on depression in primary care. Journal of the American Medical Association, 273, 1026-1031.

_ , Robinson, P., Von Korff, M., et al (1996)

A multifaceted intervention to improve treatment of depression in primary care. Archives of General Psychiatry, 53, 924-932.

_ , Von Korff, M., Lin, E., et al (1999) Stepped collaborative care for primary care patients with persistent symptoms of depression. Archives of General Psychiatry, 56, II09-1II5.

Kemp, R., Hayward, P., Applewhaite, G., et al (1996) Compliance therapy in psychotic patients: randomised controlled trial. British Medical Journal, 312, 345-349.
Myers, E. D. \& Branthwaite, A. (1992) Out-patient compliance with antidepressant medication. British Journal of Psychiatry, 160, 83-86.

_ \& Calvert, E. J. (1973) The effect of forewarning on the occurrence of side-effects and discontinuance of medication in patients on amitriptyline. British Journal of Psychiatry, 122, 46I-464.

— \& _ (1984) Information, compliance and sideeffects: a study of patients on antidepressant medication. British Journal of Clinical Pharmacology, 17, $21-25$.

Peveler, R., George, C., Kinmonth, A.-L., et al (1999) Effect of antidepressant drug counselling and information leaflets on adherence to drug treatment in primary care: randomised controlled trial. British Medical Journal, 319, 612-615.

Robinson, G. L., Gilbertson, A. D. \& Litwack, L (1986) The effects of a psychiatric patient education to medication program on post-discharge compliance. Psychiatric Quarterly, 58, II3-118.

Spooren, D., Van Heeringen, C. \& Jannes, C. (1998) Strategies to increase compliance with out-patient aftercare among patients referred to a psychiatric emergency department: a multi-centre controlled intervention study. Psychological Medicine, 28, 949-956.

Wilkinson, G., Allen, P., Marshall, E., et al (1993) The role of the practice nurse in the management of depression in general practice: treatment adherence to antidepressant medication. Psychological Medicine, 23, 229-237.

Yousef, F. A. (1983) Compliance with therapeutic regimens: a follow-up study for patients with affective disorders. Journal of Advanced Nursing, 8, 513-517.

\section{REFERENCES}

Anderson, I. M. (1998) SSRIs versus tricyclic antidepressants in depressed inpatients: a meta-analysis of efficacy and tolerability. Depression and Anxiety, 7 (suppl. I), II-17.
— \& Tomenson, B. M. (1995) Treatment discontinuation with selective serotonin reuptake inhibitors compared with tricyclic antidepressants: a meta-analysis. British Medical Journal, 310, 1433-1438.

Bollini, P., Pampallona, S., Tibaldi, G., et al (1999) Effectiveness of antidepressants. Meta-analysis of dose-effect relationships in randomised clinical trials. British Journal of Psychiatry, 174, 297-303.

Bruer, J.T. (1982) Methodological rigor and citation frequency in patient compliance literature. American Journal of Public Health, 72, 1119-II23.

Demyttenaere, K. (1997) Compliance during treatment with antidepressants. Journal of Affective Disorders, 43, 27-39.

Greenberg, R. P. \& Fisher, S. (1997) Mood-mending medicines: probing drugs, psychotherapy, and placebo solutions. In From Placebo to Panacea, Putting Psychiatric Drugs to the Test (eds S. Fisher \& R. P. Greenberg), pp. II5-172. New York: John Wiley \& Sons.

Haynes, R. B., McKibbon, K. A. \& Kanani, R. (1996) Systematic review of randomised trials of interventions to assist patients to follow prescriptions for medications. Lancet, 348, 383-386.

Kendrick, T. (2000) Depression management clinics in general practice? Some aspects lend themselves to the mini-clinic approach. British Medical Journal, 320, 528-529.

Montgomery, S. A. \& Kasper, S. (1995) Comparison of compliance between serotonin reuptake inhibitors and tricyclic antidepressants: a meta-analysis. International Clinical Psychopharmacology, 9, 33-40.

Nichol, M. B., Venturini, F. \& Sung, J. C.V. (1999) A critical evaluation of the methodology of the literature on medication compliance. Annals of Pharmacotherapy, 33, $531-540$.

Steffens, D. C., Krishnan, K. R. \& Helms, M. J. (1997) Are SSRIs better thanTCAs? Comparison of SSRIs and TCAs: a meta-analysis. Depression and Anxiety, 6, 10-18. 